\title{
Democracia e pós-democracia no pensamento político de Jacques Rancière a partir das noções de igualdade, ética e dissenso
}

Democracy and post-democracy in the political thought of Jacques Ranciere considering the notions of equality, ethics and dissensus

No centro da reflexão política do filósofo Jacques Rancière estão os conceitos de democracia, dissenso e igualdade. Em vários de seus textos (Rancière, 2004, 2010a, 2011a, 2011b), ele argumenta que a democracia não pode ser confundida com uma forma de governo ou um modo de vida social. De modo geral, para ele, a democracia é "a instituição da própria política, de seu sujeito e da forma da relação entre termos contraditórios que definem um sujeito" (Rancière, 2010a, p. 32). A política - vista não como disputas de poder e sim como a criação dissensual de cenas, argumentos e modos de visibilidade - e a construção do sujeito político (e de suas ações) enquanto "ser de fala" e "ser igual" definem o modo como a democracia se configura na reflexão de Rancière. Para ele, a democracia se traduz pela ação política que confronta e perturba a ordem consensual de funcionamento do Estado (chamada pelo autor de ordem policial). Tal ação é desenvolvida, segundo Rancière, pelo demos, pelas pessoas que não se confundem com uma coleção de membros da comunidade, nem com as classes trabalhadoras do povo ou os excluídos, de forma geral. "Elas

É mestrando pelo Programa de Pós-Graduação em Comunicação Social da Universidade Federal de Minas (Belo Horizonte, MG, Brasil). E-mail: thales.lelo@gmail.com

** É professora do Programa de Pós-graduação em Comunicação Social da Universidade Federal de Minas (Belo Horizonte, MG, Brasil). E-mail: angelasalgueiro@gmail.com

"Em meu trabalho, tentei conceitualizar a prática democrática como a inscrição da parte daqueles que não possuem parte - o que não significa os excluídos, mas qualquer um. Essa inscrição é feita por recém chegados, que permitem que novos objetos apareçam como preocupações comuns, e novas vozes apareçam e sejam ouvidas" (Rancière, 2010a, p. 60). 
são uma parte suplementar na relação da contagem das partes da população, tornando possível identificar a parte dos não contados no contexto do todo da comunidade" (Rancière, 2010a, p. 33). A figura do demos, ou dos "sem-parte", relaciona-se menos aos sujeitos em si, e mais às operações simbólicas e práticas políticas que dão a ver a existência de lógicas que definem quem pode e quem não pode fazer-se visível, audível e considerável como um igual.

Assim, interessa a Rancière identificar como a democracia se constitui como forma de agir político por meio da inscrição e enunciação dos sujeitos em uma cena de dissenso, que se cria e se recria por meio de suas ações. Ao definir a política como a "cena na qual se colocam em jogo a igualdade ou a desigualdade dos parceiros de conflito enquanto seres falantes" (Rancière, 1995, p. 81), Rancière nos fornece pistas para entendermos como as relações intersubjetivas devem se configurar em uma cena na qual um jogo comunicativo e dissensual se desenvolve e auxilia os indivíduos a se constituírem como sujeitos emancipados enquanto, ao mesmo tempo, coloca em xeque uma ordem dominante que apaga conflitos, diferenças e resistências. Contrapondo-se a Habermas ${ }^{2}$ e à estrutura de um "mundo comum" sustentado pela racionalidade, universalidade e consenso, Rancière afirma que a política precisa contemplar também a relação desigual que se estabelece entre os interlocutores, além da configuração da própria situação de comunicação/ interlocução (Marques, 2013a).

A razão pela qual a política não pode ser identificada com o modelo da ação comunicativa é que ele pressupõe que os parceiros já estejam constituídos enquanto tais, e as formas discursivas das trocas implicariam uma comunidade de discurso na qual os constrangimentos já estariam explicitados. O que é próprio do dissenso é que os parceiros não estão de antemão constituídos, nem o objeto de discussão e nem mesmo a cena de conflito. Aquele que deseja mostrar que faz parte de um mundo comum que o outro não vê, não pode se valer de uma lógica normativa implícita (Rancière, 2004, p. 244).

\footnotetext{
A distinção que Rancière estabelece entre seu pensamento político e a Teoria da Ação Comunicativa não se configura como uma crítica aprofundada. Trata-se menos de um movimento de se posicionar "contra"Habermas - afinal Rancière também está tratando da interlocução comunicativa - e mais um movimento de reafirmar seu argumento de que a essência da política é o dissenso (em Habermas, o dissenso perturba o alcance do entendimento). Em Rancière, o consenso não significa concordância argumentativa, mas a vitória da ordem policial que a todos parece incluir, diminuindo, assim, as chances de ocorrer uma divisão no senso comum, uma disputa sobre o que é dado e sobre o enquadramento segundo o qual vemos algo que é dado" (Rancière, 2004, p. 69). Para uma reflexão mais detalhada acerca da oposição entre Habermas e Rancière, ver Marques (2013a).
} 
A ação política para Rancière, então, diz respeito à proposição de contextos, de situações comunicativas que constroem as posições dos sujeitos em um cenário que é fruto da combinação entre argumentos e encenação dramática. Tal combinação deriva do fato de que, segundo Rancière (1995), a argumentação política é, ao mesmo tempo, a construção racional de pontos de vista e a demonstração de um mundo possível no qual tais pontos de vista podem contar como argumentos. É por isso que, ao lado da argumentação, Rancière salienta a existência de uma dramatização (própria da cena teatral) na qual os sujeitos podem ser quem são e podem ser "outra coisa", isto é, ter uma existência política para além do nome e do lugar que lhes foi atribuído pela ordem consensual. Sob esse aspecto, os pobres, os trabalhadores e as mulheres, por exemplo, podem deliberar sobre questões administrativas, revelando que não é necessário ser especialista para exercer o poder. E eles podem fazer isso, segundo Rancière, desde que não restrinjam suas demandas a necessidades particulares, mas que as traduzam e as aproximem de demandas coletivas. É esse movimento de tradução que Rancière associa à igualdade e a uma desidentificação que posiciona os sujeitos em um movimento de constante conexão e desconexão com os "nomes" que os caracterizam e que caracterizam suas lutas.

Não há vida política, mas cena política. A ação política consiste em mostrar como político o que é visto como social, econômico ou doméstico. Ela consiste em borrar as fronteiras. Isso é o que acontece quando agentes "domésticos" - trabalhadores ou mulheres, por exemplo - reconfiguram sua luta/disputa como luta concernente ao comum, ou seja, concernente à qual lugar pertencem ou não e quem é capaz ou incapaz de proferir enunciados e fazer demonstrações sobre o comum (Rancière, 2011a, p. 4).

De acordo com Rancière, o que constitui o espaço político está intimamente ligado a um conflito de enunciação que surge quando, na cena de dissenso, os "sem-parte" não tomam a palavra a partir do lugar que lhes foi atribuído sociologicamente, mas se inscrevem na cena por meio do discurso, da argumentação e dos recursos poéticos da experiência, afastando-se do espaço e do status que lhes foi designado pela ordem policial. Os "sem-parte" se desidentificam quando desejam mostrar que existem, para além dos nomes e atributos que lhes foram atribuídos pela ordem policial, outros nomes que identificam suas demandas como coletivas e os identificam como 
capazes de desenvolver habilidades que vão além daquelas que geralmente lhes são atribuídas.

No entanto, a atuação criativa daqueles que não são contados como sujeitos politicamente relevantes é minada pelo que Rancière chama de transformação de uma comunidade política em uma comunidade ética "que junta povos e partes singulares em um único povo que é supostamente contado como igual" (Rancière, 2010b, p. 189). Na comunidade ética, o suplemento do demos não aparece mais, uma vez que todos estão incluídos. A comunidade ética e consensual é aquela que partilha o comum de forma não litigiosa, mas sim unificadora. Essa comunidade também é saturada, um corpo coletivo com seus lugares e funções alocados de acordo com competências específicas (e desiguais) de grupos e indivíduos, sem espaço para excessos (Rancière, 2011b). Essa imagem traçada para caracterizar a comunidade atual retrata a descrença de Rancière com relação à democracia (ou, como veremos, à pós-democracia), uma vez que esse regime reitera a redução da política ao discurso homogeneizador do Estado ou da lei, promovendo um lastro consensual para a coexistência.

A democracia em Rancière apresenta, portanto, uma face positiva e uma negativa. Em sua dimensão positiva, a democracia se confunde com a ação política e com a verificação da igualdade pretensamente existente entre os indivíduos, configurando-se como outra forma de montar a cena política, "ao produzir diferentes relações entre palavras, os tipos de coisas que elas designam e os tipos de práticas que desenvolvem" (Rancière, 2010a, p. 54). Em sua dimensão negativa, a democracia, ou melhor, a pós-democracia se confunde com um ambiente: "[E]la é mais habitat do que luta; é o espaço/cenário no qual nos encontramos ao invés de uma posição requerendo sacrifício e decisão" (Rancière, 2004, p. 75). Nas seções seguintes, tentaremos explicitar melhor as diferentes dimensões do conceito de democracia desenvolvido por Rancière, incorporando as críticas tecidas às suas proposições nesse âmbito e finalizando com sua abordagem do que seria a pós-democracia. Nosso objetivo ao ressaltar esses dois âmbitos do pensamento do autor, é revelar uma concepção de política que poderia tanto trazer novas esperanças de redefinição dos modos de organização e distribuição do comum (que define quem toma parte de uma comunidade e como se dá sua participação) quanto mapear seu diagnóstico pessimista com relação ao funcionamento democrático das sociedades contemporâneas. 


\section{Democracia e governo daqueles que não contam}

Em diversas passagens ao longo de sua obra, Rancière se dedica a formular um conceito de democracia. Contudo, a definição ofertada pelo autor ganha contornos mais definidos quando ele distingue o que é ou não democracia. Por exemplo, em uma entrevista concedida a Davide Panagia, essa construção conceitual assim se manifesta:

[A] democracia não é um regime político, no sentido de uma forma constitucional, nem mesmo um modo de vida (como aprendemos através da sociologia Tocquevilliana) ou a cultura do pluralismo e da tolerância. A democracia é, propriamente dizendo, a instituição simbólica do político na forma do poder daqueles que não são designados a exercer o poder - uma ruptura na ordem da legitimidade e da dominação. A democracia é o poder paradoxal daqueles que não contam: a contagem daqueles que não são contados (Rancière, 2000, p. 124, grifos nossos).

Ao examinarmos a citação acima de maneira segmentada, podemos inicialmente afirmar que a democracia não se refere a uma forma constitucional. Isso porque, para o autor, aquilo que é chamado atualmente de "governo democrático", de fato nada mais é que uma aristocracia (Rancière, 2010a). A ordem que se autoproclama como legítima carrega consigo o dever de distribuir os nomes que os sujeitos devem ter e as posições que devem ocupar no âmago da vida pública. No liberalismo, quem assume essa função é o Estado. Como Todd May (2009) salienta, no regime atual o Estado atua enquanto um distribuidor, e aquilo que ele pretende distribuir é a igualdade, traduzida sob a forma de lei. O paradoxo dessa proposição se enuncia da seguinte maneira: se a igualdade presume uma horizontalidade entre interlocutores, como então pode um dos polos do intercâmbio assumir o papel de "agente democrático" provedor da igualdade? Tal maneira de pensar a democracia hierarquiza os corpos: há um conjunto de nomes de sujeitos a quem é outorgado o direito de impor a outros uma maneira de ser e pensar. Sob esse aspecto, Rancière (2006) irá falar das incursões militares recentes promovidas pelos Estados Unidos ao Iraque como exemplos ideais desse regime: a democracia e a igualdade se tornam "bens" a serem disseminados (mesmo que à força) àqueles que ainda não tiveram a suposta competência de reconhecer suas benesses. Estes outros se tornam inimigos da democracia e devem ser exterminados. 
O caso dos conflitos bélicos travados no Oriente Médio é uma das pontas extremas de uma problemática definição da democracia que Rancière traz para sua discussão. Ela aponta para a questão de que, se há um regime constitucional próprio da democracia, calcado em igualdade de condições, por exemplo, então há aqueles que fazem parte do regime (que já foram marcados com o brasão da igualdade) e há, do outro lado, aqueles que não são reconhecidos nessa ordem e que, por sua vez, não podem participar da vida comum e não podem falar sobre ela legitimamente até que cedam aos seus desígnios (esse tema será retomado na discussão acerca da pós-democracia).

Mas se a democracia não se identifica com uma constituição particular, também não é propriamente um modo de vida. Quando Rancière tece suas críticas a essa forma de pensar a democracia, ele o faz correlacionando correntes teóricas contemporâneas fundadas por autores como Alexis de Tocqueville, Jürgen Habermas e Hannah Arendt, com um filão do pensamento clássico grego, proveniente de Aristóteles e Platão. Diante de autores de épocas tão diferentes, o traço unificador que Rancière encontra reside na maneira como as reflexões se aproximaram no intuito de identificar qualidades e competências que possam distinguir, sem muitas ressalvas, aqueles que são hábeis em atuar no espaço público de discussão dos interesses partilhados (que são destinados à política) e aqueles que se ocupam mais intensamente de sua própria vida privada - e que, por isso, não possuem tempo ou habilidades necessárias para tomar parte em debates mais amplos.

O autor retoma, a partir de Platão, uma questão central para essa concepção da democracia: por que alguns tomam a posição daquele que governa enquanto outros se submetem e obedecem? A partir dessa indagação, são listadas diferentes disposições antropológicas para governar (boa nascença, riqueza, força, ciência, autoridade) que envolvem a distribuição de lugares e funções aos sujeitos. Mas tais "disposições para" a governança devem ser complementadas pelas "disposições para" a submissão, quais sejam, a ausência das qualidades acima mencionadas. Essa é a "ordem natural das coisas", o comando quase mítico do pastor sobre seu rebanho - comando que, por sua vez, instala uma desigualdade fundamental entre as posições possíveis de serem assumidas pelos sujeitos. É criada uma dicotomia entre "a obscuridade da vida doméstica e privada e a radiante luminosidade da vida pública dos iguais" (Rancière, 2001, p. 10). E nessa oposição o que é retirado do domínio comum assume duas formas: "uma configuração explícita que denega direitos 
políticos para certas partes da população com base em critérios de gênero, de classe ou étnicos; e uma implícita que restringe a esfera da cidadania a um tipo determinado de instituições” (Rancière, 2010a, p. 57) 3 .

Mas há uma interrupção, um intervalo nessa maneira de distribuir os lugares e os nomes com base em sua valoração para o bem comum. Em Platão, como destaca Rancière (2006), a ordem pode também estar ancorada em um "governo pela chance". Sob esse aspecto, pelo sorteio de dados se define quem é o governador. Esse sorteio não pressupõe nenhuma qualidade especial, nenhuma competência que promova a distinção entre o líder e seus subordinados. Essa nomeação, sem uma "disposição ao comum" já legitimada, leva ao governo aqueles que não são mais qualificados para governar do que para ser governados. Isso acontece porque um bom governo deve também ser feito por aqueles que não anseiam o poder, que não se "dispõem a" a governar pela posse de virtudes que se acoplam ao seu nome e que revelam constantemente a sua disposição pelo comum.

Essa democracia, que pode ser também entendida como pluralismo nos termos de uma entrada na vida pública sem uma insígnia de valor reconhecido, é a fonte de desconfortos teóricos que de Platão persistem até a contemporaneidade. Rancière afirma que o filósofo grego descrevera, tomando por referência o "governo pela chance", um estado de coisas caótico, no qual a cidade democrática estaria com seus valores invertidos, com sua ordem natural comprometida: “[A]o invés de governar, os governantes tinham que obedecer, (...) pais obedeciam seus filhos, e os velhos imitavam os novos, e no qual as mulheres e os escravos são livres como homens e senhores"

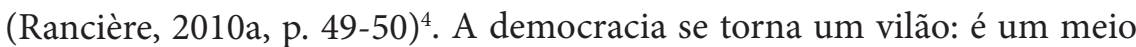
de minar a autoridade, a disciplina e o sacrifício associado aos interesses comuns (Samuel Huntington); é o reino da "tirania da maioria", das massas

\footnotetext{
A explicação que Platão encontra para a ordem social emerge em um momento em que surgira o demos na sociedade grega. Segundo Oliver Davis (2010), o demos do qual Rancière fala apareceu em 594 antes de Cristo, quando as reformas de Solon aboliram a escravidão, permitindo o surgimento de uma classe de sujeitos que não possuíam nenhum dos atributos tradicionais para a vida pública (riqueza, nascença ou excelência moral), mas que, ainda assim desejavam participar do processo político. Esse desejo fundou o dano inaugural, que revelou que aqueles compreendidos pelo demos não eram contados na sociedade.

4 Como explica Peter Hallward (2009), o estado de coisas caótico descrito por Platão não só é decorrente de o demos ter alcançado o governo, mas também da expansão do teatro. Platão exclui ambos da esfera pública. Rancière percebe que esse incômodo em Platão deriva de seu entendimento de que a mimeses confundiria a ordem das coisas e das distribuições. No teatro, os atores são seduzidos a agir de modo diferente dos papéis atrelados a seus lugares funcionais e distribuídos previamente.
} 
descontroladas, sem nenhuma aptidão para a tomada de decisões (Alexis de Tocqueville); é a expansão das diferentes opiniões individuais, que não se encontram para o debate (Gustave Le Bon).

Mas, nesse movimento, Rancière percebe que a democracia, enquanto ruptura com um "modelo natural" de ordenação dos corpos, também é $a$ instituição simbólica do político na forma do poder daqueles que não são designados a exercer o poder. No "governo pela chance", a democracia revela que a verdadeira essência da arte de governar é a sua ausência de essência. Se qualquer um pode assumir a governança por um simples lance de dados, então não há nenhuma "disposição natural" ao comando, essa "disposição" é contingente.

A democracia, inscrita sob a contingência da definição dos lugares e das posições a serem assumidas pelos sujeitos, aponta para uma igualdade que há no seio de toda desigualdade: o poder que os governantes exercem sobre os seus governados é sustentado por uma capacidade de compreensão mútua que conecta ambos. Para que uma distribuição desigual das coisas e dos lugares faça sentido é preciso que os envolvidos na partilha ${ }^{5}$ sejam capazes de falar e de entender uns aos outros: “[P]ara obedecer a uma ordem (...) deve-se compreender a ordem e deve-se compreender que é preciso obedecer-lhe. E, para fazer isso, é preciso já ser o igual daquele que manda" (Rancière, 1996, p. 31). A "ordem natural" das coisas é corroída por essa "igualdade de inteligências", que cria um hiato entre o que uma configuração do comum permite ver (sujeitos que ordenam publicamente e vozes passivas que acatam) e o que ela realmente opera (sujeitos em conexão de compreensão e, ao mesmo tempo, desconectados pelas posições diferentes implicadas em seus nomes). Em outras palavras, o poder do melhor (obtido por atributos de nascença, riqueza etc.), só pode existir a partir do "poder dos iguais".

\section{Democracia e igualdade}

Jacques Rancière constatou a existência da igualdade de inteligências entre as pessoas a partir da história do pedagogo francês Joseph Jacotot, contada em $O$ mestre ignorante: cinco lições sobre a emancipação intelectual (Rancière, 2002). Nela, o protagonista, exilado no período pós Revolução Francesa,

"A partilha do sensível faz ver quem pode tomar parte no comum em função daquilo que faz, do tempo e do espaço em que essa atividade se exerce. Assim, ter esta ou aquela'ocupação' define competências ou incompetências para o comum" (Rancière, 2005, p.16). 
acaba chegando a Flandres, região norte da Bélgica, e lá se encontra diante da difícil tarefa de ensinar para alunos que só sabiam holandês flamenco, enquanto ele só sabia o francês. Jacotot tenta quebrar essa grande barreira inicial através da criação de um ponto comum entre ele e seus estudantes: indica a eles a leitura de Telêmaco, em francês, e solicita que, após a leitura, todos escrevam suas impressões da obra nesse idioma. O professor esperava que as interpretações fossem rudimentares ou mesmo incipientes, já que esses sujeitos estavam privados de explicações e desmobilizados pelas dificuldades impostas por uma nova língua. Mas o que ele encontrou nos trabalhos de seus alunos foi um material de extrema qualidade, tão rico "como somente os próprios franceses poderiam fazê-lo" - segundo sua concepção até então. Jacotot conclui dessa experiência que, se mesmo sujeitos abandonados à sua própria sorte podem virtualmente compreender o que outros fizeram e apreenderam, é possível então que "toda inteligência seja igual e que esta igualdade seja um pressuposto que requer demonstração e não uma meta que precisa ser alcançada" (Rancière, 2000, p. 122). Assim, a "igualdade de inteligências" não presume que todas as manifestações de inteligência sejam equivalentes entre si, mas sim que "a mesma inteligência capaz de fazer poemas fictícios, invenções políticas ou explanações teóricas, é a mesma inteligência que compreende as sentenças em geral" (Rancière, 2011a, p. 14) ${ }^{6}$.

Sob esse viés, a igualdade não é um desígnio ou objetivo a ser atingido. Ela é descrita por Rancière como uma premissa que permite a distribuição desigual dos lugares a serem ocupados pelos sujeitos e que, portanto, deve ser questionada e verificada através da constante encenação argumentativa e dramática de um dano ${ }^{7}$. Este último expõe uma forma problemática de inscrição dos sujeitos no comum que aparta aqueles que podem "fazer" política daqueles que devem se submeter a leis e regras.

6 Nas palavras de Todd May, "se tomamos a igualdade de inteligências em um senso mais cotidiano para indicar que somos capazes de construir vidas significativas ao lado de e em interação com outros, então o conceito de igualdade de inteligências se torna mais convincente e mais relevante politicamente" (May, 2010, p.77).

Na cena conflitual da política, um dano é nomeado e apresentado como algo que expressa a falha da ordem social policial em reconhecer a igualdade que deveria existir entre as partes que integram uma comunidade. Segundo Rancière, o dano não é uma injúria pontual causada a um indivíduo ou grupo, deixando-os à espera de uma compensação. "Não há possibilidade de reparação do dano, mas há um lugar comum polêmico para o tratamento do dano e para a demonstração da igualdade" (Rancière, 2004, p.121). 
Rancière argumenta também que a igualdade não é ponto de partida para que os sujeitos, em situação de paridade (garantida pela universalidade da lei), estabeleçam trocas comunicativas a fim de definir um comum, isto é, "um espaço polêmico de confronto entre formas opostas de definição do que deve ser compartilhado" (Rancière, 2009, p. 277). Pelo contrário: ela assegura a troca política justamente por ser algo a ser declarado, posto à prova e verificado constantemente pelos sujeitos. A política, segundo ele, se constitui justamente porque coloca em questão a pretensa igualdade que existiria entre os sujeitos que participam da vida política de uma comunidade e que seria assegurada pelos direitos. Esse questionamento da igualdade permite a exposição de um dano na medida em que revela que, originalmente, existem parcelas que não são contadas como parte efetiva de uma comunidade, ou seja, existem sujeitos que são vistos como incapazes de aportar contribuições significativas para a vida em comum. Sob esse aspecto, é possível afirmar que a "cena do conflito político é constituída por meio da verificação da igualdade dos falantes em uma cena de desigualdade e explicitação de um dano, fazendo com que esse espaço comum apareça via desentendimento" (Dean, 2011, p. 91).

Se a igualdade não é um pressuposto e se, na ordem vigente, ela é constantemente camuflada por nomes atribuídos aos sujeitos, conferindo-lhes consideração e valorização diferenciadas em razão de sua "disposição" ou não para a vida pública - lançando às margens do privado aqueles que não deveriam fazer mais que obedecer aos comandos -, então é possível, em uma dada situação, verificar a contingência dessa distribuição desigual. O processo de verificação da igualdade envolve a ação criativa e poética de evidenciar, nas partilhas até então traçadas (isto é, as distribuições do visível, do audível e do enunciável), os hiatos que o consenso pretende apagar, de modo a permitir a instauração de cenas polêmicas. Em tais cenas, segundo Rancière, se conforma um processo democrático tramado como "a ação de sujeitos que, trabalhando no intervalo entre identidades, reconfiguram as distribuições do público e do privado, do universal e do particular" (Rancière, 2006, p. 61). Sua conceituação carrega uma potência crítica, já que a democracia é concebida como uma força de igualdade nas engrenagens da dominação, de modo a se exprimir como aquilo que afasta a política de ser um simples reforço da lei.

\section{Democracia e desidentificação}

Aqui nos aproximamos da noção de democracia construída pelo filósofo e apresentada como "o poder paradoxal daqueles que não contam: a contagem 
daqueles que não são contados" (Rancière, 2004, p. 52). O poder daqueles que não estão computados na soma das partes dos designados para a vida pública é o de evidenciar as incongruências na própria contagem, as distâncias que existem entre os nomes dos sujeitos, com suas topografias demarcadas e sua ordem tracejada (ordem que divide o poder pela nascença, pela riqueza e pela competência), e as práticas que se configuram nas situações concretas, e que revelam, por meio de uma desidentificação, que é possível assumir mais que um nome restrito a um universo de interesse particular.

Em linhas gerais, a desidentificação dá a ver uma constante conexão e desconexão entre nomes que definem para o sujeito político seu lugar em uma comunidade. A lógica da subjetivação política não é jamais a simples afirmação de uma identidade, ela é sempre, ao mesmo tempo, a negação de uma identidade imposta por um outro, fixada pela lógica policial. A polícia deseja nomes exatos, que marquem para as pessoas o lugar que ocupam e o trabalho que devem desempenhar. A política, por sua vez, diz de nomes "impróprios" que apontam que sujeitos podem ser mais que o script definido pelo lugar que ocupam socialmente: os nomes que recebem e que não se "adéquam" à classificação policial manifestam, como vimos, a presença de um dano.

A igualdade é então avaliada em situação, mas não em prol de uma identidade que unificaria os indivíduos em um termo comum, mas sim através das distâncias que são arquitetadas entre eles e seus diversos nomes. Por esse prisma, a democracia é um processo contra a privatização da vida, é um processo de alargamento da esfera pública e do comum que define a forma de uma comunidade que ganha corpo quando essa esfera assume uma forma polêmica, como anteriormente ressaltado.

É importante ter em mente que o comum, para Rancière, não existe em si e por si mesmo, mas se produz no movimento no qual ele é colocado em questão, no centro de um conflito dissensual sobre a existência de uma cena comum e sobre a existência e qualidade daqueles que nela se fazem presentes e que tentam, por meio de suas ações e enunciações, tratar um dano. É o movimento ininterrupto de definição e redefinição do comum que delineia os traços mais marcantes da política segundo Rancière, visto que ele a define como fruto de um processo de desentendimento que se desdobra em uma "cena na qual se colocam em jogo a igualdade ou a desigualdade dos parceiros de conflito enquanto seres falantes" (Rancière, 1995, p. 81). Assim, nem os 
sujeitos políticos nem a cena na qual se desenvolvem suas ações são vistos como já dados, mas ganham corpo quando são explicitadas as fronteiras que definem quem faz parte do comum e quem dele está alijado.

Em $O$ desentendimento, Rancière fala de um "dispositivo ternário" que se manifesta na democracia enquanto interrupção da distribuição não problemática dos nomes de um sujeito em função de suas "competências para" participar do comum: 1) "a democracia é o tipo de comunidade que é definido pela existência de uma esfera de aparência específica do povo" (Rancière, 1996, p. 102) - essa aparência não é uma ilusão que se opõe ao real, mas sim a introdução, no âmbito da experiência, de um "visível que modifica o regime do visível" (Rancière, 1996, p. 102); 2) O povo que toma esse campo de aparências não se enquadra em definições sociológicas e étnicas - o povo (demos), por intermédio do qual há democracia, é "a instituição de sujeitos que não coincidem com partes do Estado ou da sociedade, sujeitos flutuantes que transtornam toda representação dos lugares e das parcelas" (Rancière, 1996, p. 103); por fim, 3) Rancière argumenta que a aparência desse povo é o lugar de condução de um litígio, que não é um conflito de interesses, mas "uma interlocução que põe em jogo a própria situação de interlocução" (Rancière, 1996, p. 103).

O "dispositivo ternário", que associa o aparecer do demos para o tratamento litigioso de um dano, pode ser ativado como cena democrática em qualquer lugar (May, 2009). Na "ordem natural" os atores se constroem em suas situações de fala sem questionar os lugares que ocupam na sociedade - ainda que a distribuição desigual de posições entre eles só seja possível por meio de um pressuposto de igualdade. Mas essa contingência da "ordem natural" é continuamente passível de ser averiguada por essa mesma premissa. Nas palavras de May, "a democracia política pode emergir em qualquer lugar, desde o espaço de trabalho, passando pela sala de aula até o teatro ou a rua" (May, 2009, p. 17). Mas por que nem sempre isso ocorre?

Rancière vem sendo criticado exatamente nesse ponto por autores como Paulina Tambakaki (2009). Para ela, a filosofia política do autor permite entrever o litígio instaurado no dispositivo ternário da democracia ocorrendo somente em momentos raros, pontuais - e nem sempre eficazes. E, se a política é rara, ela pode nunca ocorrer, e pode nunca revigorar o regime constitucional ou uma maneira particular de distribuição desigual dos nomes e espaços a serem associados aos sujeitos. Acreditamos, contudo, que há uma 
incompreensão por parte dessa autora do que está sugerido no pensamento político de Rancière. Em um texto recente, o próprio autor respondeu a esta crítica da seguinte forma:

Não significa que eu reduzi a política a momentos excepcionais e evanescentes. A mera encenação do político raramente aparece em uma forma pura, mas há política em uma porção de meios "confusos" e conflituosos, e a política faz uma memória, uma história. E há uma dinâmica histórica da política: uma história dos acontecimentos que rompem com o curso "normal" do tempo (Rancière, 2011a, p. 5).

Tendo isso em mente, importante é ressaltar que a política e a democracia em Rancière não são raras, já que a aparente fugacidade delas é, na realidade, uma característica que as impede de serem elevadas a um nível ontológico (como se houvesse um modo próprio da política, um tipo de inscrição padronizada para a democracia nas cenas). A interrupção na "aparência visível" e pretensamente natural dos corpos pode acontecer de muitas maneiras, e precisa ser acompanhada em ato, em sua realização (Deranty, 2003). Nessas ações concretas de verificação da igualdade, o pensamento de Rancière, como aponta Christian Ruby (2007), evidencia uma profunda confiança na capacidade dos sujeitos de interromper o curso presente do mundo, apostando, para tal, em uma política da ação, e em uma democracia que evoca que “o fim da ação não é só o de se inserir dentro daquilo que já existe, mas de constantemente redesenhar a instância da vida comum” (Ruby, 2007, p. 166).

A compreensão da política como ação que promove rupturas na ordem consensual por meio do dissenso é retomada por Rancière em uma entrevista concedida a Max Blechman et al. (2005). Nela, os entrevistadores interrogam-no se a atenção para as situações em que são criadas irrupções à "ordem natural" tem como ponto de chegada a utopia de uma comunidade política ideal. Em sua resposta, Rancière salienta que está menos preocupado com os resultados dos movimentos de reconfiguração do sensível do que com o "empoderamento das atuais capacidades de qualquer um através da prática dissensual" (Rancière, 2005, p. 292). Isso porque, se estivesse imersa em cada manifestação da política a peça de um quebra-cabeça que levasse a um projeto futuro em que fosse possível encaixar todos os itens em seus devidos lugares, então não haveria mais espaço para o dissenso. Para Rancière, tal projeto de "comunidade por vir" remete à proposta de Platão de uma comu- 
nidade consensual concreta - forma de organização em que não restariam partes não registradas na conta da sociedade ou mesmo oportunidades para que a "ordem natural" da distribuição de papéis e lugares fosse abalada por elementos litigiosos.

Com essa argumentação, o autor advoga em favor de uma emancipação avaliada enquanto processo, e não a partir de seus resultados. Dentre os leitores críticos de Rancière, Todd May (2010) é aquele que mais acompanha tal linha de raciocínio, assegurando também que, se o movimento emancipatório fosse subordinado aos seus resultados factíveis (a reorganização do sensível efetuada), haveria a tendência de que fosse desqualificado em seu caráter político, caso não atingisse um objetivo pré-estipulado estrategicamente. Assim, a avaliação sobre o que seria ou não política seria realizada não a partir da emergência de uma cena de dissenso em sua materialidade, mas por forças externas que se responsabilizariam em julgar, de fora da ação, sua efetivida$\mathrm{de}^{8}$. Nesse horizonte, ficaria perdido um elemento importante da política emancipatória e da democracia, que é o processo de reconfiguração das vidas daqueles que participaram de uma cena de dissenso na ocasião de sua materialização (incluídos aqui também aqueles que se viram repentinamente em uma situação na qual elementos antes não visíveis e audíveis em seu campo de percepção passaram a existir). Nas palavras de May, "um movimento que surge a partir da pressuposição da igualdade, mas que não atinge um impacto, é falho. Contudo, é um movimento democrático" (May, 2010, p. 78).

Mas a preocupação de Rancière (e de alguns de seus leitores) com o momento em que é construída uma cena de dissenso, dirigindo uma atenção contínua para o processo de verificação da igualdade em seu devir pode, entretanto, levar a uma apreensão restritiva da democracia e a uma visão trágica da história, que praticamente anula a esperança que mobiliza sujeitos a lutarem em busca de transformações sociais (sobre o que, como será visto adiante, o próprio Rancière já procurou discorrer). $\mathrm{O}$ esclarecimento do segundo ponto tornará o primeiro mais claro. Como tratado anteriormente através da remissão a Platão, "a ordem natural das coisas" é a desigualdade na distribuição dos corpos na comunidade política, responsável pela exis-

Todd May ilustra essa problemática da seguinte forma: "Imagine um movimento que emerge a partir da pressuposição de igualdade, mas que enfrenta uma ordem policial tão entrincheirada que falha em promover mudanças na referida ordem. Se a ausência de sucesso foi relevante para a questão de qual movimento é democrático, então o caráter democrático do engajamento político não seria mais definido pelo demos, mas por forças externas a ele" (May, 2010, p.78). 
tência de elementos não contados na soma das partes da sociedade. Mas são esses elementos que têm o potencial para instituir, pela democracia, a ação política emancipatória, revelando, na criação de uma cena litigiosa (que se vale do axioma da igualdade de inteligências) um procedimento contínuo de verificação da igualdade. Tal procedimento expõe as fraturas na forma desigual de contagem dos corpos, vozes e lugares de existência e "aparência" que era efetuada até então.

Porém, se toda ordem é "naturalmente" desigual, como expõe Oliver Davis (2010), então qualquer tentativa de redistribuição igualitária promovida por mecanismos instituídos só promoveria a reprodução da desigualdade (ainda que se possa falar em piores e melhores ordens policiais, nos termos de Rancière). Isso porque a distribuição presume um distribuidor, e, para Rancière, a igualdade não implica passividade, mas sim um interesse ativo dos sujeitos envolvidos que sofrem com um dano. Mas não só as boas intenções de organismos instituídos estão comprometidas nessa visada. Em uma ação política emancipatória bem-sucedida, o resultado, na melhor das hipóteses, é uma reconfiguração da ordem do sensível. Mas quando a cena de dissenso se aquieta, a forma de contagem das partes da sociedade continua desigual em sua contingência característica. Bruno Bosteels (2009) conclui desse raciocínio que a história para Rancière estaria subsumida às práticas opressivas e de dominação. Para esse autor, as conjunturas históricas no pensamento de Rancière estariam determinadas enquanto sucessivas épocas cobertas por uma forma invariante de política (policial), a qual possui uma "propriedade imprópria", que é a de possuir um segredo, qual seja, a igualdade de todos com todos que serve como base do abismo original na ordem comunitária. Sob esse aspecto, há uma despolitização histórica das mudanças sociais e uma associação da face estatal da política a um destino (pois as formas "policiais" são constantes ao longo do tempo).

Sendo a "ordem natural" contingente um "destino", e levando em consideração que, pelo princípio da igualdade de inteligências, não é possível dizer que existam atores mais conscientes das formas de exploração e de opressão do que as próprias subjetivações políticas que derivam do demos (ou sem-parte $)^{9}$, logo a ação emancipatória perde de vista toda a esperança de

Conforme observado por Deranty (2003), pela conduta epistemológica de Rancière não é possível dizer que o intelectual tem mais consciência da exploração do que aqueles que são explorados (o papel do investigador neste sentido seria só o de ajudar os sujeitos a expressar sua própria experiência). 
mudança que a envolve: se os sujeitos já sabem o que é necessário para criar uma cena polêmica, e se sabem que ao final de sua mobilização não terão bons resultados, ou mesmo poderão vislumbrar profundas transformações na sociedade (mesmo em um futuro longínquo), então por qual razão eles agem?

$\mathrm{Na}$ entrevista acima referida que Rancière concedeu a Max Blechman et al. (2005), essa questão desponta de outra maneira, ou seja, com os entrevistadores interrogando o autor sobre a tragicidade de seu pensamento político, que percebe as rupturas como continuamente reincorporadas à ordem policial. Rancière responde aos entrevistadores que o que é visto por eles como uma "reincorporação" das irrupções à distribuição hierárquica dos corpos em comunidade, por ele é avaliado enquanto um processo de "sedimentação", em que se constrói uma "viva memória da política" que poderá ser reencenada em uma ocasião posterior oportuna, levando a novas inscrições da igualdade que se valem de leis, instituições sociais constituídas etc.. Em suas palavras, "os lugares de sedimentação são também lugares para inscrição de significantes democráticos que podem abrir, e que abrem, novos espaços para o dissenso" (Rancière, 2005, p. 298). Por isso, ainda que considere as realizações operadas pela ação política como provisórias, não as aprecia como trágicas.

Porém, se novamente retomarmos o movimento de Rancière de refletir sobre a desigualdade, considerando como iguais aqueles que a ordem social julga como desprovidos de competências para tomar parte no comum (de forma a acompanhar seus anseios na construção de cenas litigiosas), não parece fazer muito sentido que esses sujeitos sejam motivados a dar início a um procedimento de verificação da igualdade e expor um dano sem esperanças outras que não as de uma remota possibilidade de sedimentarem os resultados de suas ações políticas em um tipo de memória histórica (que poderá ou não ser reavivada no futuro). Os sujeitos organizam suas esperanças e desejos em prol de emancipação e de reformulação concreta da ordem vigente (o que não quer dizer que eles aspiram a que ela se torne outra ordem, mas sim que ela ao menos poderá se transmutar, após a ação, em um tipo de organização social mais afeita a considerar a igualdade um princípio de interlocução entre coletivos). Como Alberto Toscano (2011) afirma, mesmo que os momentos políticos sejam raros e se manifestem confusamente, não é possível desconsiderar que, em sua emergência, eles visam a mais do que sua breve continuidade pode oferecer no curto prazo de um litígio. 
Toscano ressalta que a "emancipação é um processo que não pode ser simplesmente reduzido à afirmação da igualdade, mas envolve a necessidade de nos voltarmos em direção à investigação das condições para a instituição e durabilidade da igualdade" (Toscano, 2011, p. 232). Segundo o pesquisador italiano, com essa meta em vista, o reconhecimento da não naturalidade da dominação se torna mais um motivo para investigar sua especificidade (o que é diferente de assumi-la como um destino incontornável). Nessa investigação, pode-se gerar um pensamento contra-hegemônico passível de se tornar uma criativa oposição a desigualdades estruturais, interferindo na ordem vigente e rastreando maneiras de produzir conhecimento emancipatório, afinal, é preciso conhecer algo para se opor a ele (Toscano, 2011). Em suma, para esse autor, se Rancière não reconhece a determinação da ação que faz com que sujeitos criem uma cena dissensual visando a transformações concretas nas partilhas do sensível (e não só sedimentações mnemônicas), passa então "a eternizar a invariante e transcendental estrutura da dominação e da incapacitação (a polícia)” (Toscano, 2011, p. 232).

Peter Hallward (2009) faz coro às críticas acima tecidas ao pensamento político de Rancière, chegando à constatação de que a concepção de democracia desse autor é restritiva e quiçá inconsequente. Se "a política é mais um meio de reconhecer uma desautorização e deslegitimação generalizada do que uma forma de participar em processos agonísticos nos quais as pessoas se tornam autorizadas, de forma inédita, por meio de um princípio ativo de militância" (Hallward, 2009, p. 155), então o que se perde aqui é um olhar para a determinação da ação. Para Hallward, Rancière não olha para as lutas que perduram na cena pública e que necessitam de organização, de fidelização, de tomada de posição (para além da manifestação da irrupção). O que pode ocorrer, por fim, é que o pensamento de Rancière recaia em um olhar inconsequente da democracia, que supõe que o jogo da igualdade e da política possa por si só bastar para a construção de cenas dissensuais sólidas. O risco disso é acabar em um "reino de substancializado da imaginação", ótimo para as teorizações, mas pouco operacionalizável na prática concreta da luta política (Hallward, 2009).

\section{Pós-democracia na contemporaneidade}

Ao argumentar que a democracia não pode ser caracterizada exclusivamente pela universalidade da lei, Rancière (2010a) defende a ideia de que, 
uma vez que a universalidade é constantemente privatizada pela lógica da ação governamental, o universal tem que ser suplementado por formas de subjetivação e casos de verificação que impeçam a acelerada privatização da vida pública. Contudo, ele aponta que a subjetivação política e a verificação da igualdade encontram-se em dificuldades no modelo democrático pautado pelo neoliberalismo. Nesse modelo, a democracia "não é mais percebida como o objeto de uma escolha, mas vivida como ambiente familiar, como o habitat natural do individualismo pós-moderno, não mais impondo lutas e sacrifícios em uma contradição extrema com os prazeres da era igualitária" (Rancière, 2010b, p. 75). Essa democracia vivida é mais ambiente do que luta; é o espaço/cenário no qual nos encontramos ao invés de uma posição requerendo sacrifício e decisão. Como habitat, a democracia assume uma faceta ética.

No que se refere à guinada ou virada ética da política, Rancière (2010b) enfatiza que a ética se configuraria hoje como a colonização do fato pelo direito, ou seja, a supressão da divisão entre fato e direito ${ }^{10}$, que define um modo de estruturação simbólica da comunidade responsável por afastar o dissenso e estabelecer a identificação de todas as formas de discursos e de práticas sob o mesmo ponto de vista indistinto: o ponto de vista consensual. O consenso, segundo ele, não deixa que surjam intervalos entre o vivido e a norma: ele força uma coincidência entre ambos. Seu objetivo seria o de produzir uma sobreposição entre leis e fatos, de modo que as leis se tornassem idênticas à vida social, preenchendo intervalos e espaços vazios (Marques, 2013b).

A pós-democracia é descrita por Rancière (2010b) como uma democracia que elimina a aparência e a disputa, ficando reduzida aos mecanismos do Estado e da combinação/troca de interesses. Essa democracia do consenso destrói a disputa e marca a redução da política ao discurso consensual do estado ou da lei, que promove mais do que um lastro consensual para a coexistência. A pós-democracia cimenta o programa do Estado, impõe uma percepção unidimensional do mundo em que conflitos e desentendimentos foram banidos do reino da visibilidade, da cena de aparência, retornando somente sob formas malignas, sob o signo da supressão e eliminação da alteridade (Tambakaki, 2009, p. 102). O consenso apaga a política porque ela está no dissenso, na luta e na contestação.

\footnotetext{
${ }^{10}$ A distinção entre fato e direito, entre ser e dever ser, é feita no intuito de salientar que as experiências não podem ser subsumidas, dirigidas e reguladas pelas normas sob o risco de uma diluição da especificidade das práticas políticas, culturais e sociais dos sujeitos.
} 
O consenso estabelece então um enquadramento conceitual e imagético para qualquer interação e discussão, cujas contradições passam despercebidas por coincidirem com interesses hegemônicos ou por refletirem situações existentes e vistas como inalteráveis. Por isso, ele reduz o processo político a um jogo de especialistas (Rancière, 2004). Se, por um lado, não há sujeito (nem comunidade) sem normas, de outro, reduzi-lo e reduzir suas experiências ao âmbito da normatividade significaria uma adequação perfeita à regulação institucional e estatal.

Na pós-democracia, segundo Rancière, "a comunidade política tende a ser transformada em uma comunidade ética, que junta povos e partes singulares em um único povo que é supostamente contado como igual" (Rancière, 2010b, p. 189). Todos estão incluídos. Os excluídos não são mais atores conflituais, mas aqueles que acidentalmente se encontram fora da grande igualdade de todos, para quem a comunidade precisa estender a mão a fim de restabelecer o vínculo social. Na comunidade política, aqueles que não são contados como parte, como parceiros iguais, aparecem como sujeitos políticos suplementares, portando um direito que ainda não foi reconhecido ou testemunhando uma injustiça no estado de direito existente. Mas na comunidade ética esse suplemento não aparece mais uma vez que todos são considerados partes integrantes de um coletivo.

Essa imagem traçada para caracterizar a comunidade atual retrata a descrença de Rancière com relação à democracia institucional, uma vez que esse regime reitera a redução da política ao discurso consensual do Estado ou da lei, promovendo uma dissociação entre experiências e normas. Por isso, ele opõe à comunidade ética uma comunidade de partilha. Esta última resulta do processo de verificação da igualdade, uma vez que ela cria um espaço que pressupõe a partilha da mesma razão, mas também um espaço no qual a unidade só existe em uma operação de divisão: "uma comunidade polêmica de partilha suscitada por impor uma consequência não reconhecida da igualdade garantida por lei” (Rancière, 2004, p. 166).

Alberto Toscano (2011) é um dos críticos dessa descrença de Rancière para com os tempos atuais, e diz que ela deriva da própria lógica argumentativa do autor. Segundo Toscano, Rancière pensa a ordem existente como contingente, e acredita que todo esforço por tentar encontrar uma ordem nessa lógica só pode levar à reprodução da dominação. Não há gradações nesse tipo de pensamento, e toda ideia de ordem social é concebida ou como 
contingente ou como "natural" (como anteriormente foi discutido). Assim, pensar a dinâmica econômica contemporânea seria atuar junto ao mercado neoliberal (polícia), e pensar na necessidade da economia seria levar a uma desconfiança ainda maior com a honestidade do propositor. A ideia de "realismo" também só seria a duplicação da realidade como destino dentro do sistema consensual, e a "necessidade" uma tautologia (tal qual sua asserção axiomática sobre a igualdade).

Por essa visada, não surpreende que a política seja percebida como "rara" em tal conceituação, já que ela só ocorreria para fora de todas as redes de organização social existentes. Menos improvável ainda seria dizer que vivemos tempos apolíticos, já que, em tal definição de política, quaisquer épocas seriam apolíticas (Toscano, 2011). Jodi Dean (2011) também acompanha essa crítica, diagnosticando que, ao contrário do que apresenta Rancière com a ideia de pós-democracia, nos tempos atuais cada vez menos as pessoas se encontram em situação de mútuo entendimento (como nas conversas em redes sociais entre pessoas que partilham entre si uma igual incompreensão mútua). Nesse sentido, a autora defende que seria necessária a presença mais incisiva da ordem policial em determinadas circunstâncias, como para excluir grupos fundamentalistas da distribuição já desigual dos corpos em comunidade ou mesmo para proteger sujeitos fragilizados por uma condição de expropriação e opressão.

\section{Considerações finais}

As relações traçadas entre os conceitos de dissenso, política, igualdade e democracia no pensamento de Rancière suscitam, como vimos, várias críticas. Consideramos relevante retomá-las brevemente para, em seguida, apresentar como Rancière nos fornece alguns pontos de esperança para a democracia no horizonte de uma cena consensual dominante.

Uma primeira crítica remete ao entendimento de política como momento pontual, e não como processo. Autores como Slavoj Žižek (2004) e Peter Hallward (2009) afirmam que Rancière não explica por que e como exatamente a política irruptiva irá perturbar a ordem policial, e nem como as irrupções darão origem a um processo de mudanças que se sustente ao longo do tempo. Para ambos, os desdobramentos do enfrentamento polícia/ política são pouco explorados, sendo que a política poderia se resumir a uma ação provocadora, perturbadora, que interrompe o fluxo de operações 
da ordem policial, mas que acaba se configurando como pontual, sem um planejamento para a efetiva incorporação das mudanças reivindicadas.

Os efeitos da política entendida enquanto criação de uma cena teatral de dissenso são esporádicos e intermitentes. Uma vez que a cena é desmontada, resta pouco ou nada. Uma sequência de improvisação é difícil de ser mantida a longo prazo. Falta investir em um tipo de poder que a política tenha de impor uma mudança efetiva na configuração de uma situação (Hallward, 2009, p. 152).

Žižek (2004) comenta que Rancière resiste em desenvolver melhor apontamentos sobre o processo por meio do qual esses momentos de distúrbio (ou "explosões democráticas momentâneas" que minam a ordem policial estabelecida) são reabsorvidos por essa ordem que pretendem reconfigurar. Com isso, ele estaria negligenciando uma segunda dimensão que é vital para a política emancipatória, ou seja, a dimensão processual que desempenha o papel de traduzir/inscrever a explosão democrática na ordem policial, impondo à realidade social uma nova ordem.

Uma segunda crítica, que está intimamente ligada à anterior, de certo modo, sustenta que, para Rancière, a política é um tipo de desautorização generalizada ou de deslegitimação da polícia - mais do que uma questão de participação em processos agonísticos por meio dos quais as pessoas se tornam politicamente autônomas (Tambakaki, 2009). Tal crítica pode ser expressa através das seguintes questões: "Em que medida a ordem policial se apresenta vulnerável diante das investidas perturbadoras da cena de dissenso? A concepção de igualdade de Rancière é só transgressiva, provocativa, ou aponta para mudanças mais profundas?” (Hallward, 2009, p. 153).

Davis (2010) tenta questionar a invalidação do pensamento de Rancière a partir da oposição "pontual $v s$. processual", que supostamente caracterizaria sua concepção de ação política, afirmando que Rancière não desconsidera ser necessário levar em conta o processo de inscrição e mobilização que segue o momento da revolta. Antes de tudo, é importante dizer que Rancière nunca estabeleceu uma separação dicotômica entre ação política de ruptura e ação política de consolidação de mudanças de longo prazo. Apenas ele se mostra mais enfaticamente preocupado com o processo político-poético de criação e instauração de cenas de dissenso pelos sujeitos políticos quando desejam colocar à prova o estatuto igualitário que lhes é garantido pelas leis e normas. 
Para entrar em uma troca política, torna-se necessário inventar a cena na qual as palavras ditas se tornam audíveis, na qual os objetos podem se fazer visíveis e os indivíduos podem ser reconhecidos. É nesse sentido que podemos falar de uma "poética da política" (Panagia, 2000, p. 116).

A ação política para Rancière necessita, portanto, de uma combinação de dois procedimentos que, ao contrário do que indicam os críticos, não podem ser separados. De um lado, ela precisa de momentos poéticos nos quais se formam "novas linguagens que permitem a redescrição da experiência comum, por meio de novas metáforas que, mais tarde, podem fazer parte do domínio das ferramentas linguísticas comuns e da racionalidade argumentativa” (Rancière,1995, p. 91). E, de outro, a ação política requer um investimento gradativo dos sujeitos em uma comunicação argumentativa e dialógica capaz de permitir a verificação da igualdade e a transformação de vozes desorientadas em discursos de contestação e resistência. "Assim, não se pode separar uma ordem racional de argumentação de uma ordem poética do comentário e da metáfora, pois a política é produzida por atos de linguagem que são, ao mesmo tempo, argumentações racionais e metáforas poéticas" (Rancière, 1995, p. 86).

Em suma, a situação de comunicação instaurada nas cenas de dissenso marca não só a importância da contextualização, do reconhecimento e da visibilidade dos interlocutores, mas também a tematização argumentativo-poética de um objeto/questão percebido como pertencente ao âmbito do "comum".

Por fim, uma terceira crítica endereçada a Rancière pode ser articulada a partir da seguinte provocação: como o dissenso pode ser benéfico para práticas democráticas? Vimos que a democracia institui, mas não facilita o litígio político, ainda menos hoje. Quando Rancière fala a respeito da pós-democracia, ele busca justamente investir na restauração de práticas políticas dissensuais em meio a um avassalador ambiente de concordância e desmobilização gerado por uma ética que não enxerga a igualdade como processo de constante verificação, mas como ponto de partida que, a priori, afirma a inclusão legal de todos na comunidade. Apesar desse esboço sombrio do que seria a atuação da ética no âmbito político atual, Rancière aponta que, antes de remeter às normas, a ética deveria ser examinada a partir de duas dimensões principais: ethos como modo de ser, como modo de vida que garante aos sujeitos o estabelecimento de uma identidade e vínculo com um entorno; e, em segundo lugar, ethos como princípio de ação. Por meio desse 
segundo sentido, a ética também apresentaria um caráter social, pois, embora centrada no indivíduo, ela é domínio de inter-relação, das relações sociais no interior das instituições e das comunidades. A ética estaria associada, no âmbito da comunidade e de suas ações e práticas, à atribuição a cada um da sua parte, sendo cada um destinatário de uma partilha justa.

É possível dizer que, de modo geral, a questão da ética em Rancière é dada pelo modo como a partilha do sensível é realizada. Dito de outro modo, são as formas de partilha do sensível que definem a maneira como os indivíduos se relacionam, nomeiam o que consideram justo ou injusto e constituem o comum que os articula em uma comunidade. A ética associada à partilha do sensível promovida pela polícia privilegia os sujeitos cuja ocupação (trabalho) e posição social definem e atestam suas competências ao comum, fazendo-os visíveis e audíveis em um espaço discursivo. Já a partilha do sensível promovida pela política visa retirar os corpos de seus lugares assinalados, configurando uma comunidade de partilha e libertando-os de qualquer redução à sua funcionalidade. Nesse sentido, a democracia se configura como comunidade de partilha nos dois sentidos do termo: uma adesão a um mundo que só pode ser expresso em termos antagônicos (divisão) e um estar juntos (compartilhamento) que só pode assumir a forma de um conflito (Rancière, 2004).

A partilha do sensível assim concebida instaura um conflito acerca do que significa falar, assim como sobre os horizontes de percepção que distinguem o audível do inaudível, o compreensível do incompreensível, o visível do invisível. A ética vista sob esse aspecto restituiria à democracia seu caráter de insurgência, de ruptura, de reconfiguração do imaginário através da criação de cenas dissensuais nas quais a igualdade é constantemente posta em questão. O dissenso alimenta a prática democrática quando atravessado pela estética, quando dá a ver cenas, personagens, manifestações e enunciações que constroem um tipo de participação que implica a constante reinvenção dos sujeitos e dos espaços de sua "aparência”. Rancière (2004) ressalta que a permanência da democracia não está associada ao preenchimento de todos os tempos mortos e espaços vazios por formas de participação e de contra-poder, mas à renovação constante dos atores e de suas ações. Por isso, a experiência democrática dissensual é também permeada pela estética: o sujeito democrático é um ser que toma a palavra diante do outro, e é também um sujeito poético que reconfigura materialmente e simbolicamente o território do comum. 


\section{Referências}

BLECHMAN, Max; CHARI, Anita \& HASAN, Rafeeq (2005). "Democracy, dissensus and the aesthetics of class struggle: an exchange with Jacques Rancière”. Historical Materialism, v. 13, n. 4, p. 285-301.

BOSTEELS, Bruno (2009). "Rancière leftism, or, politics and its discontents", em ROCKHILL, Gabriel \& WATTS, Philip (eds.). Jacques Rancière: history, politics, aesthetics. Durham and London: Duke University Press. DAVIS, Oliver (2010). Jacques Rancière. Cambridge: Polity Press.

DEAN, Jodi (2011). "Politics without politics", em BOWMAN, Paul \& STAMP, Richard (eds.). Reading Rancière. London: Continuum.

DERANTY, Jean-Philippe (2003). "Rancière and contemporary political ontology”. Theory \& Event, v. 6, n. 4, p. 21-42.

HALLWARD, Peter (2009). "Staging equality: Rancière's theatrocracy and the limits of anarchic equality”, em ROCKHILL, Gabriel \& WATTS, Philip (eds.). Jacques Rancière: history, politics, aesthetics. Durham, London: Duke University Press.

MAY, Todd (2009). "Democracy is where we make it: the relevance of Jacques Rancière". Symposium: Canadian Journal of Continental Philosophy, v. 1, n. 13 , p. 3-21.

(2010). "Wrong, disagreement, subjetification", em DERANTY, Jean-Phillipe (ed.). Jacques Rancière: key concepts. Durham: Acumen. MARQUES, Ângela (2013a). "Três bases estéticas e comunicacionais da política: cenas de dissenso, criação do comum e modos de resistência”. Contracampo, v. 26, n. 1, p. 126-145.

(2013b). "Aspectos éticos, poéticos e comunicacionais do pensamento político de Jacques Rancière”. Logos, v. 20, v. 2, p. 111-121. PANNAGIA, Davide (2000). "Dissenting words: a conversation with Jacques Rancière”. Diacritics, v. 30, n. 2, p. 113-126.

RANCIÈRE, Jacques (1995). La mésentente: politique et philosophie. Paris: Galilée.

(1996). O desentendimento: política e filosofia. São Paulo: Editora 34. (2000). Le partage du sensible: esthétique et politique. Paris: La Fabrique.

(2001). “Ten thesis on politics”. Theory \& Event, v. 5, n. 3, p. 1-16. (2002). O mestre ignorante: cinco lições sobre a emancipação intelectual. Belo Horizonte: Autêntica. 
(2004). Aux bords du politique. Paris: Gallimard.

(2005). A partilha do sensível: estética e política. São Paulo: EXO Experimental.

(2006). Hatred of democracy. London: Verso.

(2009). "The method of equality", em ROCKHILL, Gabriel

\& WATTS, Philip (eds.). Jacques Rancière: history, politics, aesthetics.

Durham, London: Duke University Press.

(2010a). “Does democracy means something?", em Dissensus: on politics and aesthetics. London: Continuum.

(2010b). “The ethical turn of aesthetics and politics", em Dissensus: on politics and aesthetics. Londres: Continuum.

(2011a). "The thinking of dissensus: politics and aesthetics", em BOWMAN, Paul \& STAMP, Richard (eds.). Reading Rancière. London: Continuum.

(2011b). "Against an ebbing tide: an interview with Jacques Rancière", em BOWMAN, Paul \& STAMP, Richard (eds.). Reading Rancière. London: Continuum.

RUBY, Christian (2007). "Le sens de l'action dans la philosophie de Jacques Rancière”. Le philosophoire, n. 29, p. 165-182.

TAMBAKAKI, Paulina (2009). "When does politics happen?”. Parallax, v. 15 , n. 3, p. 102-113.

TOSCANO, Alberto (2011). "Anti-sociology and its limits", em BOWMAN, Paul \& STAMP, Richard (eds.). Reading Rancière. London: Continuum. ŽIŽEK, Slavoj (2004). “The lesson of Rancière”, em RANCIÈRE, Jacques. The politics of aesthetics. London, Continuum.

\section{Resumo}

O objetivo deste artigo é explicitar melhor as diferentes dimensões do conceito de democracia desenvolvido por Jacques Rancière, destacando três aspectos conceituais específicos. Os conceitos de igualdade e dissenso definem a democracia como ação política e processo de verificação da igualdade assegurada pela lei, configurando-se como outra forma de montar a cena política dissensual. Já o conceito de ética assume a função de explicar o que Rancière chama de pós-democracia, ou seja, a democracia como ambiente, como cenário em que a vida se submete à lei. Nosso objetivo ao ressaltar esses dois âmbitos do pensamento do autor é revelar tanto uma concepção de política que poderia, talvez, trazer novas esperanças a partir de um conceito de política baseado em formas 
dissensuais de comunicação e expressão que inventam modos de ser, ver e dizer a fim de redefinir os modos de organização e distribuição do comum que define quem toma parte de uma comunidade e como se dá sua participação e produção de novas formas de enunciação coletiva, quanto um diagnóstico pessimista feito pelo autor com relação ao funcionamento democrático e ético das sociedades contemporâneas.

Palavras-chave: democracia; Jacques Rancière; igualdade; ação política; ética; dissenso.

\section{Abstract}

The aim of this article is to elucidate the different aspects of the concept of democracy developed by Jacques Rancière, drawing attention to three specific conceptual dimensions. The concepts of equality and dissent define democracy as political action and process of verification of the equality assured by law, configuring another manner to create the political scene of dissensus. On the other hand he concept of ethics assumes the function to explain what Rancière call democracy as surrounding (habitat), as a scene where life is dominated by the law. In highlighting these two aspects of Rancière's thought we intended to both disclose a pessimistic diagnosis regarding the democratic and ethical functioning of the contemporary societies and bring hope by a conception of politics based on the dissenting forms of expression and communication which invent ways of being, seeing and saying in order to redefine the ways of organization and distribution of the common which defines who takes part of a community and how the citizens can participate and produce new forms of collective enunciation.

Keywords: democracy; Jacques Rancière; equality; political action; ethics, dissensus.

Recebido em 30 de setembro de 2013.

Aprovado em 21 de dezembro de 2013. 